\title{
Energy saving control system development for external lighting
}

\author{
A.A. Ashryatov, V.G. Kulikov, A.V. Panteleyev \\ Federal State Budgetary Educational Institution of Higher Education "National Research Mordovia State University \\ named after N. P. Ogarev", Russia
}

\begin{tabular}{l}
\hline \hline Article Info \\
\hline Article history: \\
Received Jun 1, 2019 \\
Revised Sep 25, 2019 \\
Accepted Oct 11, 2019 \\
\hline Keywords: \\
Automation \\
Economy \\
Electronic Pra \\
Energy Saving \\
Lighting \\
Sodium Lamps \\
\hline
\end{tabular}

\begin{abstract}
Currently, energy saving requires the development of simple and efficient street lighting control systems. In order to create such a control system, it is necessary to develop an original principle of its operation. They considered the advantages of electronic starting devices in street lighting control systems. They performed the analysis of the existing state of street lighting means, their shortcomings and solutions have been determined, and they developed the method of lighting device automatic control. They performed the assessment of the economic effect from loss reduction associated with reactive power and due to power reduction during deep night. They presented the example of economic effect achievement from the use of an electronic starting device with automatic power reduction.
\end{abstract}

Copyright () 2020 Institute of Advanced Engineering and Science. All rights reserved.

\section{Corresponding Author:}

A.A. Ashryatov, Federal State Budgetary Educational Institution of Higher Education,

"National Research Mordovia State University named after N. P. Ogarev", Russia.

Email: ashryatovaaA.A547@gmail.com

\section{INTRODUCTION}

Modern street lighting systems are quite energy-intensive engineering structures. The activities for the introduction of energy-saving technologies in such systems bring tangible economic effect [1]. Savings are achieved in various ways, one of them is the use of modern, more efficient light sources and power sources. Currently, sodium lamps (HPS) are the best solution for street lighting. They best combine such parameters as price, quality and reliability.

Traditionally, the lamps are powered from some AC network with the frequency of 50/60 Hz using electromagnetic ballast (EmPRA), which is not able to stabilize the power when the mains voltage and the lamp characteristics of the lamp are deviated during operation. If mains voltage is increased, the lamp overheats, accompanied by the processes leading to its intense wear and reduced service life [2-11].

EmPRA is a nonlinear load, so the spectrum of current consumption contains higher harmonics that cause resonance phenomena at higher harmonic frequencies, the distortion of supply voltage form, voltage drop in the distribution network, heating and additional losses in transformers and supply wires and capacitor heating [3].

\section{MATERIALS AND METHODS}

The use of electronic PRA for outdoor lighting. The modern alternative to electromagnetic ballast is an electronic control device (EPRA). The use of EPRA allows to eliminate the above-mentioned disadvantages and to achieve the optimal control of RLVD in working and anomalous modes [4].

Nowadays, it is considered that the cost-effective solution for urban lighting energy efficiency improvement is the rejection of EmPRA use in favor of EPRA with automatic luminous flux control function. This will significantly improve both the energy characteristics of outdoor lighting networks without additional 
costs for the reconstruction of electrical engineering industry, and the quality of artificial lighting $[5,6]$.

Active losses in EPRA during the tests at the nominal voltage of $220 \mathrm{~V}$, are slightly less than active losses in EmPRA and, in terms of light efficiency, these devices are almost the same. Therefore, when devices are compared directly, one might get the impression that, from the point of view of energy efficiency, EPRA do not have particular advantages. However, if we recall that the lighting network is a long and an extensive structure in which electrical energy must be delivered to each lighting device, then the effect of nonlinear load on three-phase $\mathrm{AC}$ network must be taken into account in order to compare the energy indicators of lighting installation correctly [6]. It is necessary to take into account the daily fluctuation of the supply voltage, especially when the supply voltage in the overwhelming number of cases at night (the main time of the lighting device operations) is higher than the nominal by 5-10\%, the power consumption of EmPRA with HPS lamp increases by $15-30 \%$, while the power consumption of EPRA remains unchanged or even decreases by 1-2\% due to increased efficiency.

Active power factor corrector is applied in EPRA [7]. Due to the high power factor (not less than 0.98) EPRA reduces the consumption of reactive power by almost 10 times as compared with EmPRA, the third harmonic level is reduced 5 times at least, the starting current is completely absent.

EPRA provides the following:

a) lamp service life increase due to power stabilization in a wide range of supply voltage variation and output mode optimization to the nominal lamp power;

b) the reduction of operating costs for the replacement of lamps due to their service life increase, as well as the practical absence of the need to replace pulsed ignition devices;

c) direct energy savings by $5-7 \%$, as compared with EmPRA, due to high efficiency ( $\geq 0.93)$;

d) high power consumption ratio $(\geq 0.98)$;

e) silent operation of a luminaire and the absence of flickering light due to the lamp power supply with high frequency current $(>100 \mathrm{kHz})$;

f) less weight and dimensions due to the operation at an increased frequency, the presence of an integrated ignition device and the absence of the need for additional equipment to compensate for reactive power;

g) the absence of current surges in the power supply network during turning on;

h) the ability to connect more luminaires to the line at the complete absence of illumination level difference factor at the beginning and at the end of the line $[8,9]$.

Microcontroller is the controlling part of EPRA. Its task is to provide the specified lamp operation modes, to implement the protective functions of EPRA, to control the lamp state, and to suppress acoustic resonance [12]. The use of intelligent EPRA will allow the incorporation of lighting systems into a single network uniting various services in order to increase energy efficiency [10].

\subsection{Comparison of EPRA and EmPRA Reliability}

Correct comparison requires full statistics. Nowadays, the data on EPRA are hypothetical, since the operating experience is in the development stage. But some aspects that provide reliability level increase have been identified.

The total number of light points with EPRA is taken and the number of removals is recorded. Objectively, the early models of EPRA essentially lost to EmPRA on this indicator, also due to the shortcomings of research in development. With the improvement of production technology, the quality of the element base, the elimination of design errors and the number of removals has significantly decreased. Accumulating operating experience, it became obvious that the dominant cause of failures is the extremely low quality of the power supply network (according to GOST 13109-97) and the noise immunity parameters of devices specified in the standards for lighting networks are understated relative to actual ones. The latest generation of EPRA are designed to meet more stringent standards in such a way as to maintain full operation after exposure to anomalous voltage surges. The initial experience of EPRA operation shows that the statement about the lower reliability of EPRA becomes controversial as compared to EmPRA. Besides, the comparison method is not always obvious.

For example, if we compare the calculated reliability of only the choke and EPRA, it is obvious that the comparison will not be in favor of the latter. But EMPRA includes the compensating capacitor and the igniting device. The reliability of these two components is significantly affected by the same factor as the reliability of EPRA [11].

The temperature of EPRA electronic components is the most important parameter for a long service life and reliability provision [13]. The most sensitive element is an electrolytic capacitor. Although EPRA are designed in such a way that the temperature of the components is minimally low for the widest possible range of applications, it is also extremely important that a luminaire design makes a significant effect on the heat removal from EPRA. The working position of EPRA, its execution should be selected depending on the final product design [14]. 


\subsection{Economic Effect from Loss Reduction Associated with Reactive Power}

During a lighting device operation based on a gas-discharge lamp, reactive power flows inevitably. But this does not mean that the reactive power must be constantly transmitted throughout the distribution network, it can be localized by putting a reactive power compensator in each lighting installation. This can be either a special compensating capacitor (in the case of electromagnetic PRA) or an active power factor corrector (in the case of EmPRA).

The economic effect of $\cos \varphi$ increase consists of the following components:

a) load reduction of power transformers (with reactive power consumption decrease, the total power consumption is reduced) [15];

b) heat loss reduction in the supply cables;

c) power load provision on the cable with a smaller cross section (without insulation overheating)

d) the connection of an additional active load due to partial current unloading of power transformers and power cables;

e) cost reduction for reactive power payment. Reactive energy payment ranges from $12 \%$ to $50 \%$ of active energy payment in various regions of Russia;

f) the suppression of network interference, the reduction of phase asymmetry, distribution network reliability increase [16].

$10-15 \%$ of the consumed active energy is lost on average in the supply cables at active facilities. Losses are proportional to the current value square flowing through the cable. For calculations, we take the loss factor $\mathrm{Kp}=12 \%$.

Let the standard value of $\operatorname{Cos} \varphi \mathrm{EmPRA}=0.85$.

After EPRA upgrade $\operatorname{Cos} \varphi=0.98$.

The relative active component of the current (coinciding by voltage phase) is taken equal to unity.

The relative total current prior to modernization $\mathrm{I}_{1}=1 / 0.85=1.176$.

The relative total current after modernization $\mathrm{I}_{2}=1 / 0,98=1,02$.

The reduction of active power consumption will be the following:

$\Delta \mathrm{Wc}=\left[\left(\mathrm{I}_{1}^{2}-\mathrm{I}_{2}{ }^{2}\right) / \mathrm{I}_{1}{ }^{2}\right] \cdot \mathrm{K}_{\Pi} \cdot 100 \%=2,97 \%$.

In this example, the cost of active energy decreased by $2.97 \%$. In the general case, the decrease of active energy consumption takes place due to the increase of $\operatorname{Cos} \varphi$ for an operating object.

$\Delta \mathrm{Wc}=\left\{\left[1 / \cos ^{2} \varphi_{1}-1 / \cos ^{2} \varphi_{2}\right] /\left[1 / \cos ^{2} \varphi_{1}\right]\right\} \cdot \mathrm{K}_{\Pi} \cdot 100 \%$, where:

$\cos \varphi_{1}$ - prior to modernization (for example, 0.5, which is typical for EmPRA with a faulty or missing compensating capacitor);

$\cos \varphi_{2}-$ after modernization (for example, 0.98)
Кп - loss ratio (for example, $\mathrm{K}_{\Pi}=0.12$ )

Then, for our example, $\Delta \mathrm{Wc}=8.88 \%$ only in the supply cables and excluding the power transformer and switchgear losses. In case of a complete replacement of EmPRA with EPRA in the lighting network, the excellent energy indicators of the latter provide the consumer with the opportunity to use all the installed capacity efficiently. For example, let $100 \mathrm{kVA}$ be allocated and lighting installations are used with the lamp power of $250 \mathrm{~W}$. Then, for the case of EmPRA use with a typical average power factor of 0.85 for the entire service life, all installed power will be selected if 310 luminaires are installed. If luminaires of similar power are used, but with EPRA, then $86.9 \mathrm{kVA}$ will be selected during the installation of 310 luminaires and the unused reserve of installed capacity of $13.1 \mathrm{kVA}$ remains, which the consumer can use at his discretion.

\subsection{Savings Due to Power Reduction}

The standards for luminous flux are tied to the intensity of road traffic. And this is reasonable - the denser the flow of cars, the more intense the driver's eyesight, the more accurately he must distinguish the details. In the interval from about $10 \mathrm{pm}$ to $5 \mathrm{am}$, the density of the traffic flow decreases and the lighting on most streets can be made less bright. This saves energy. Besides, the decrease of illumination reduces light pollution of the environment - the adverse effects of too bright lighting on nature in large cities according to environmentalists.

Currently used street lamps with sodium and metal-halogen lamps and equipped with EmPRA, are not dimmable. Therefore, until recently, it was officially authorized to turn off half of lamps along the road at 
night. The use of this method on the highway leads to the deterioration of roadway illumination uniformity, which is fraught with accident increase.

\section{RESULTS AND DISCUSSION}

The use of EPRA allows for the adjustment of high-pressure lamp POWER. The power is reduced by gradual lamp current reduction through frequency increase, which maintains the thermionic emission of lamp electrodes. Practice has shown that it is possible to reduce power for HPS and MGL lamps. With MGL power decrease, CRI color rendering index reduction takes place, starting from a certain level but this is usually not essential for street lighting.

Due to EPRA additional energy savings can be obtained by luminaire power control introduction at night. EPRA with automatic power reduction do not require expensive equipment for their work to transfer control commands. In EPRA with automatic power reduction, the so-called "night phase" mode is introduced into the microcontroller operation algorithm. There are three modes of lighting lines: evening (sunset), night and morning (dawn). In the evening mode, the lamps operate at rated power and provide the required level of illumination. Close to midnight, the power and the illumination of the luminaires are reduced. Closer to the morning, when the intensity of traffic increases, power and illumination gradually returns to the nominal level.

The work time is divided in half and thus the midpoint is obtained (Figure 1). 2 hours is subtracted from the midpoint and this will be the moment of transition to the reduced power mode. 5 hours is added to the midpoint and it will be the moment of return to full power mode. Thus, the maximum operating time in low power mode makes 7 hours. When a lamp operates in the range from 7 to 5 hours, it works only in reduced power mode. When the lamp is operating for less than 5 hours, the energy-saving mode is not turned on.
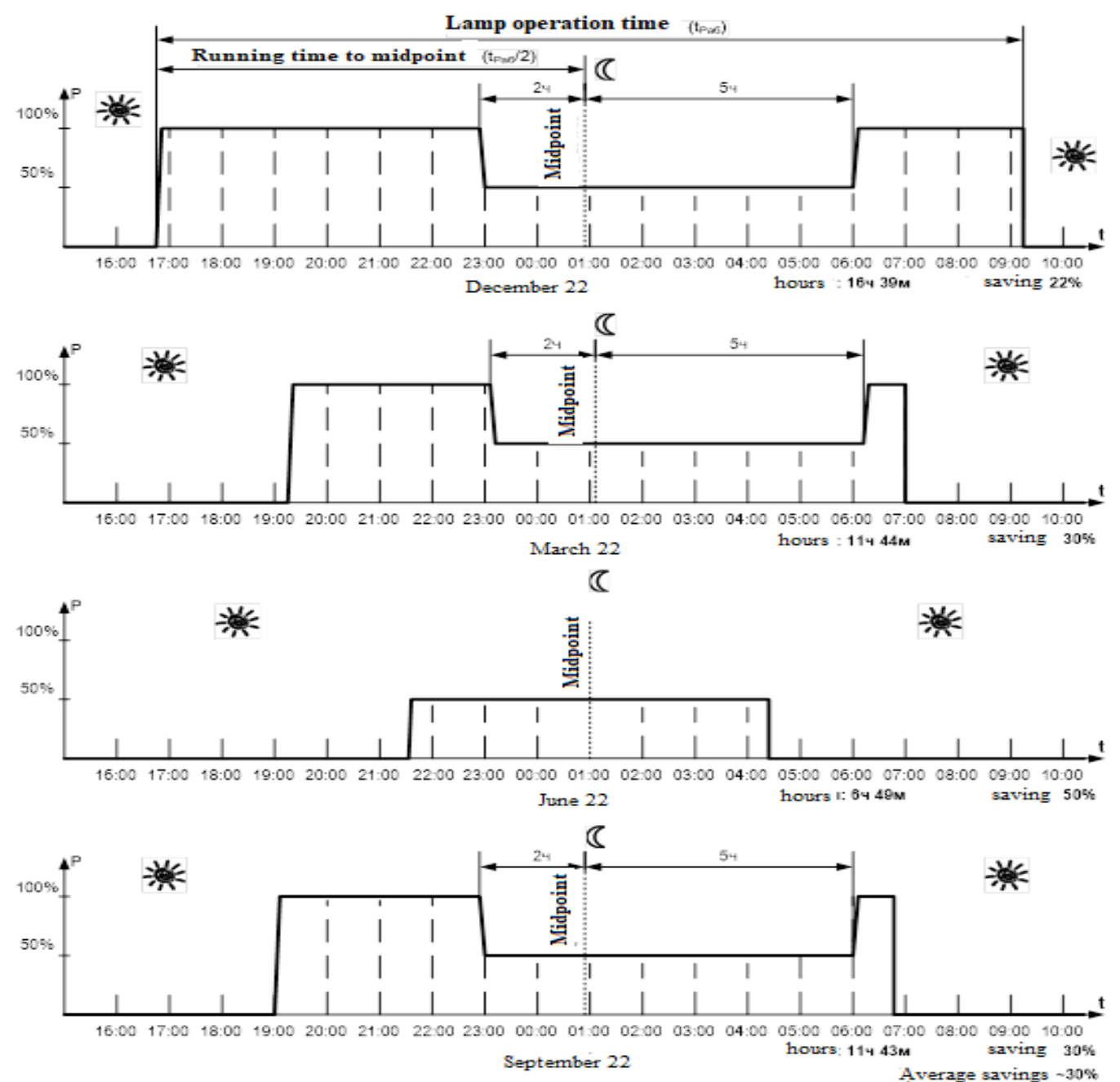

Figure 1. Power reduction algorithm during different seasons 
For different seasons of the year the lamp operation duration is different. The intelligent algorithm embedded in the microcontroller automatically determines the time of transition to the reduced power mode and return from it. EPRA microcontroller calculates the operating time of the luminaire from the moment the power is supplied until the light is turned off, and it saves the obtained value to a non-volatile memory [17-25]. To set up the luminaire for energy-saving mode, you need two switches (two nights) at least (Figure 2). This is necessary for error correction, if the lighting is turned off much earlier or later than the previous days.

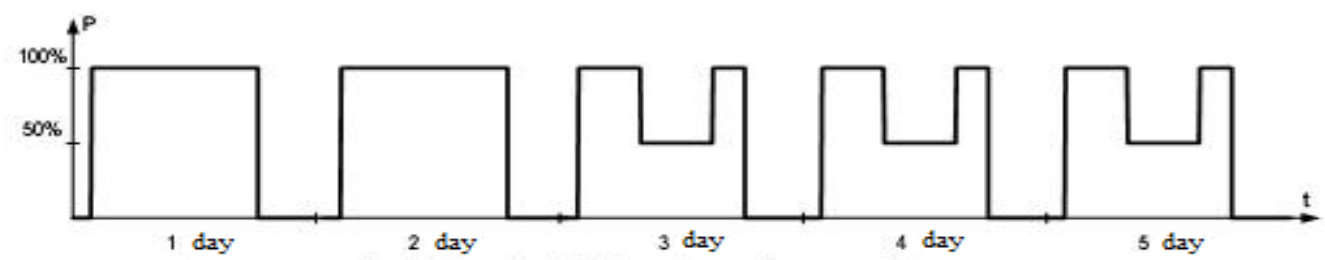

Figure 2. EPRA settings for energy saving mode

By the depth of power reduction high-pressure lamp are inferior to LEDs. Nevertheless, it was possible to reach the level quite suitable for practical applications. When you use the best models of EPRA, it is possible to reduce the luminous flux to $35 \%$ of the nominal value for HPS and to $50 \%$ for MGL.

\subsection{Technical and Economic Assessment of EPRA use with Automatic Power Reduction}

The example of economic effect achievement from EPRA is presented in Table 1.

a) The calculation of the economic effect was carried out on the basis of data obtained from MUP "GORSVET", Saransk (the average annual operating time of the lighting lines is 3840 hours / year; the cost of electricity is 6.50 rubles / $\mathrm{kW} * \mathrm{~h}$ ).

b) Throttle PRA does not have power stabilization on the lamp, the economic effect will be increased if the network voltage is too high

Table 1. The Example of Economic Effect Achievement from EPRA HPS-250-ACM

\begin{tabular}{|c|c|c|c|}
\hline Compared devices & Consumed power, $\mathrm{Wt}$ & Saving, $\mathrm{Wt}$ & $\begin{array}{l}\text { Economic effect from } 1000 \text { lamps during the operation of } 3840 \\
\text { hours per year. }\end{array}$ \\
\hline Throttle PRA & 265 & 0 & 0 \\
\hline EPRA & $265-30 \%=185,5$ & 79,5 & $\begin{array}{rl}0,0795 \mathrm{~kW} * & 3840 \mathrm{~h} / \text { year } * 6,50 \mathrm{rub} . / \mathrm{kW}^{*} \mathrm{~h}= \\
& =\mathbf{1 9 8 4} \text { rub./lamp }\end{array}$ \\
\hline
\end{tabular}

\section{CONCLUSION}

The analysis of HF power supply characteristics for RLVD allows you to select the following main advantages: 1) Saving of materials is most significant for HF devices with active correction of consumed current form; 2) Allows to increase the stability of lamps and reduce the pulsation of the light flux; 3) The lamp service life is increased; 4) The reduction of power consumption by EPRA mainly due to energy conversion loss decrease at high requency; 5) The reduction of load on the electrical networks is achieved due to higher power consumption ratio as compared to EmPRA; 6) The ability to regulate the light flux in a wide range.

The use of microcontrollers as a control device for EPRA makes it possible to implement the functions of ignition, heating, stabilization and power intelligent control on the lamp, which gives a significant economic effect from lamp service life extension and energy saving. The cost of EPRA is about 3200 rubles. A luminaire cannot be changed, you just need to replace EmPRA with EPRA, while additional equipment is not required. Tests have shown that real energy savings can reach 35\%. Considering the cost of EPRA purchase, plus their installation into lamps, the payback period for EPRA will be about 1 year.

\section{REFERENCES}

[1] V. Polyakov and I. Oshurkov, "Effective power supply FOR high-pressure discharge lamps," Power Electronics, vol. 1. no. 34. pp. 50-53, 2012.

[2] A. El Aroudi, M. Orabi, R. Haroun, and L. Martinez-Salamero, "Asymptotic slow-scale stability boundary of PFC AC-DC power converters: Theoretical prediction and experimental validation," IEEE Trans. Ind. Electron., vol. 58, no. 8 , pp. 3448-3460, Aug 2011 
[3] H.-L. Cheng, Y.-C. Hsieh, and C.-S. Lin, “A novel single-stage high-power-factor AC/DC converter featuring high circuit efficiency”, IEEE Trans. Ind. Electron., vol. 58, no. 2, pp. 524-532, Feb 2011.

[4] A. Evstifeev, "The features of ballast design for high-pressure lamps," Power Electronics, no. 3, pp. 132-136, 2008.

[5] V. D. Polyakov, and I. A. Oshurkov, "Discharge lamp power supply device," Patent for the utility model RUS 102448, $10 / 19 / 2010$.

[6] E. A. Ermakov, "Controlled EPRA for high-pressure lamps," Modern Lighting Equipment, no. 2, pp. 50-59, 2010.

[7] S.-K. Ki, D. D.-C. Lu, "Implementation of an efficient transformerless single-stage single-switch AC/DC converter," IEEE Trans. Ind. Electron., vol. 57, no. 12, pp. 4095-4105, Dec 2010.

[8] H. Ma, Y. Ji, Y. Xu, "Design and analysis of single-stage power factor correction converter with a feedback winding," IEEE Trans. on Power Electron., vol. 25, No. 6, pp. 1460-1470, June 2010.

[9] H-L Cheng, C-S Moo, C.-K. Huang, C.-S.Yang, "Analysis and implementation of a novel single-stage low-frequency electronic ballast for HID lamps" in Proc. Inter. Power Electron. Conf., pp. 384-389, 2010.

[10] J.-C. Hsieh and J.-L. Lin, "Novel single-stage self-oscillating dimmable electronic ballast with high power factor correction", IEEE Trans. on Ind. Electron., vol. 58, no. 1, pp. 250-262, Jan 2011.

[11] D. A. Salkin, and S. S. Dushutin, "Possibilities for additional service integration on technical system servicing of a residential facility into the housing and utilities information system," Modern high technologies, no. 2, pp. 83-89, 2018.

[12] C. A. Cheng, H. L. Cheng, and C. W. Ku, "Design and implementation of a single-stage acoustic-resonance-free HID lamp ballast with PFC," IEEE Transactions on Power Electron, Vol. 29, Issue: 4, pp. 1966-1976, April 2014.

[13] M. R. Banaei, A. R. Dehghanzadeh, E. Salary, H. Khounjahan, and R. Alizadeh, "Z-source-based multilevel inverter with reduction of switches", IET power electronics, vol. 5, iss. 3, pp. 385-392, 2012.

[14] D. Cao, S. Jiang, X. Yu, and F. Z. Peng, "Low-cost semi-Z-source inverter for single-phase photovoltaic systems," IEEE Trans. on Power Electron., vol. 26, no. 12, pp. 3514-3523, Dec 2011.

[15] F. Bouchafaa, D. Beriber, and M.S. Boucherit, "Modeling and control of a gird connected PV generation system," in proc. 18th Mediterranean IEEE CCA, pp, 315-320, June 23-25, 2010.

[16] S. Mishra, R. Adda, and A. Joshi, "Inverse watkins-johnson topology-based inverter," IEEE Trans. on Power Electron., vol. 27, no. 3, pp. 1066-1070, March 2012.

[17] L. Kirsten, M. A. Dalla Costa, and C. Rech, "Digital control strategy for HID lamp electronic ballasts," IEEE Trans. Ind. Electron., vol. 60, issue: 2, pp. 608-618, Feb 2013.

[18] Vahidi, H., \& Mohi Aldin Qhomsheie, M. (2015). Comparison accurate calcula numerical solution of buckling thin cylindrical shape memory alloy shell under uniform load with D.Q.M. UCT Journal of Research in Science, Engineering and Technology, 3(1), 33-38.

[19] J., Yakubu H., and Aboiyar T.. "A chaos based image encryption algorithm using Shimizu- Morioka system." International Journal of Communication and Computer Technologies 6.1 (2018), 7-11.

[20] Gamarra, M., Zurek, E., \& San-Juan, H. (2018). "Addendum for: A Study of Image Analysis Algorithms for Segmentation, Feature Extraction and Classification of Cells." Journal of Information Systems Engineering \& Management, 3(1), 05

[21] Rauf, S., Kalim, I., \& Mubeen, M. "Impact of Electronic Media on Pakistan's Security." Global Social Sciences Review, III(I), 434-446, 2018.

[22] Pourasad, Y., Mahmoodi-k, M. and Oveisi, M. "Design of an optimal active stabilizer mechanism for enhancing vehicle rolling resistance.” Journal of Central South University, 23(5), pp.1142-1151, 2016.

[23] Shah, N., Aajiz, N. M., \& Idris, M. "Failure in the English Subject in Government High Schools for Boys in District Mardan, Khyber Pakhtunkhwa Pakistan.” Global Social Sciences Review, III (II), 146-158. 2018.

[24] Saleem, M., Khan, F. A., \& Zaman, A. "Wh-Movement Pattern in the Spoken Discourse of Teachers A Syntactic Analysis.” Global Social Sciences Review, III (II), 400-420, 2018.

[25] M.S. M. Gismalla, M.F. L. Abdullah, "Performance evaluation of optical attocells configuration in an indoor visible light communication," Indonesian Journal of Electrical Engineering and Computer Science (IJEECS), vol. 14, no. 2, 668-676, 2019. 